DOI: 10.2478/ausfm-2014-0012

\title{
Seeing to Believe - Sensing to Know From Film Form to Perceptual Environment
}

\author{
Yvonne Spielmann \\ University of the West of Scotland (Ayr, United Kingdom) \\ E-mail: mail@yvonne-spielmann.com
}

\begin{abstract}
Keynote talk given at the "Cinema of Sensations" International Conference organized by the Sapientia Hungarian University of Transylvania, in Cluj-Napoca, Romania, between the $25^{\text {th }}$ and $27^{\text {th }}$ of May, 2012. (The photos of Yvonne Spielmann illustrating the article were taken by Ágnes Pethő and Ferenc Boné, and are reproduced here with their permission.)
\end{abstract}

Keywords: multisensory experience, interactive installations, Seiko Mikami, Gina Czarnecki, Masaki Fujihata.
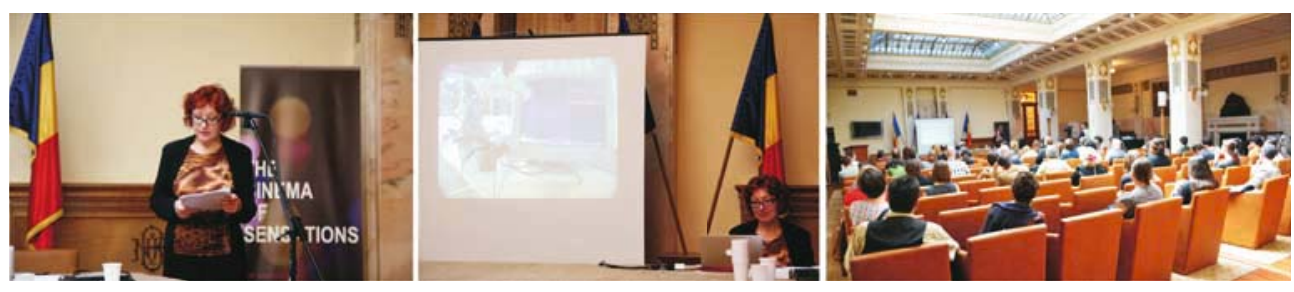

Theories and histories of film perception generally review film experience in relation to the projection of light images onto a large scale screen. With the institutionalized form of film viewing in a cinema theatre we view the world as it exists on the remote screen from safe distance. Based on this viewing situation, the discussion of image perception refers to paradoxical phenomena produced by the cinematic apparatus itself: that we are seeing a series of still images on the filmstrip as a representation of continuous movement, on the one hand; and that we are at the same time recognising the persistence of our vision which is a necessary prerequisite of the film experience, on the other hand.

This refers back to "gestalt theory" and the discovery of the persistence of vision made as early as around 1912 by Max Wertheimer. He, in scientific experiments verified the illusion of movement which occurs in the perception of two separate, fixed points or lines seen consecutively. Both parameters, the 
perception of movement and the persistence of vision, are combined in the film apparatus to constitute the effect of an uninterrupted, ordinary film viewing experiences. The fusion of the two mechanisms sustains our enjoyment of what is represented and gets reinforced in the use of the representational function of time based moving images. However, the apparatus's moving function and the perceptional consistency have also been dealt with separately. In a wider view of visual culture, the angle of sensory perception that gives rise to the illusion of consistency in the filmic image does in principle refer to a system of believing what you see. If you see things in motion you believe they are moving despite the fact that moving is an effect of the combination of individual frames that are presented at a certain frame rate. Here, perception equals visual "evidence," whereas the cognitive knowledge of the underlying constructedness of moving images triggers our intellectual capacity to understand coherence in vision as we perceive it. Throughout the history of vision in modernity both aspects, the sensing and the knowing have been subject to various experiments within and out of cinematic performance of moving images.

\section{One}

In modernity, we can roughly identify two major conceptual frameworks that have been guiding the discourses about visual recognition. They are grounded in emotional and sensational response on one end and in thought processes on the other. The first operates as a belief and witness system where you believe what you see, because you are culturally and socially trained to accept visual representation as representation of visual facts. Herby, we adapt to the presumption that any representational form of an image, be it in film, television or new media, bears a referential connection to the unfolding of the represented events in real time and space. The second discourse is based upon intellectual engagement and expert knowledge. We reflect mixed, multisensory experiences, and our own physical presence in relation to both the cognitive viewing condition and the functions of the media. On these grounds we make sense of what we perceive at a specific moment in time and space.

For long time, the two ways of visual recognition had been attributed to diverse aesthetic concepts and schools. While subjective, sensual, and emotional "feelings" guide the primary accent of seeing and believing, the other, the objectifying, scientific, and measurable accentuations of sense data foster the knowledge based appropriation of visual and furthermore multimodal stimuli. The divergent tendencies get highlighted in different approaches of modern 
painting, most prominently executed in the paradigms "to paint what you know" and "to paint what you feel," notably referring to the conceptual understanding of painting as science or imagination.

In a historical view, it is English landscape painter John Constable (1776-1837) who in the first decades of 19th century in a series of lectures on landscape painting had proposed to paint after nature in an almost scientific way. He understood painting as a scientific production of art and not as a composition out of imagination. Constable, concerned about "The decline and revival of landscape," wrote: "Painting is science, and should be pursued as in inquiry into the laws of nature. [...] In such an age as this, painting should be understood, not looked on with blind wonder, not considered only as a poetic aspiration, but as a pursuit, legitimate, scientific, and mechanical." (John Constable's Discourses 1970, 69.)

Soon thereafter photography and its technique of the variable eye that can take many shots of the same event in succession ("serial photography") had succeeded as a new art form. The expression of a variety of shots which have equal value and correspond to a variety of visual impressions meant a formidable challenge to the ruling idea of exactness in the depiction of nature in the painterly image. In result, we recognise a shift in painting that departs from objectifying science and moves towards subjective impression. This conceptual transformation strikes especially the genre of landscape painting. By the end of 19th century, what counts is the elusiveness and liveliness of the moment or many moments. The image concept that represents variability in sight is driven by the artists' expression of an immediate impression.

The most prominent examples are Claude Monet's impressionist paintings. The philosophy of his time to express one's own perception is best highlighted in the "series" paintings of Haystacks (1890-91) and Rouen Cathedral (18921894). Monet painted the same subject from variable points of view and under varying light and weather conditions, depending on the time of the day. These paintings in series not only refer to the cut in time as introduced with the interval in photography and film. More important, they ascertain sensual experience and subjective views of an eye-witness who describes respectively paints natural phenomena the way he/she experiences them sensorially at a certain moment in time and space. Clearly, there is a plenitude of such moments. This $19^{\text {th }}$ century approach toward seeing and vision is led by the convincement that visual representation of development in time has to follow the concept of compound image. This concept, then, is essentially exposed with the techniques of photography and film in the $20^{\text {th }}$ century. The compound image 
has not only manifested a "new" and futuristic vision in the paintings of Russian Constructivism, German Expressionism, and Italian Futurism, it later becomes the standard of contemporary digital image compositing in the $21^{\text {st }}$ century.

Because of the composite and variable nature of modern imagery, it comes as no surprise, when the togetherness of the two above discussed concepts, scientific, and sensual, was prominently conceptualised in film theory based on montage. Sergei M. Eisenstein in his reflections on the organisational principle of montage in formalist film praxis and theory understands the formal composition of diverse facts as a way to visibly construct difference and antagonism in film. In this, difference within the shot which is the smallest unit of montage, between the shots, and in-between the sequences has a dual meaning: it mediates and separates between contrasting, conflictuous, and heterogeneous views of reality. The contrasting composition results in film aesthetics of collision. Its form shall provoke the audience emotionally and intellectually at the same time. Eisenstein's famous montage principle of abstract concepts gets realised in the idea of an "intellectual montage" that is essentially grounded in a view of the world as compound and changeable. This notion departs from Eisenstein's earlier "montage of film attractions" which he then replaced by pathos (Battleship Potemkin, 1925) inasmuch as pathos is further replaced by ecstasy (Ivan, 1944) which is meant to activate the viewer's emotional and intellectual responsiveness. By pairing

"pure feeling" and "sensation" with awakening, the formalist filmmaker and theoretician Eisenstein aims in two directions. He wishes to emotionalise thinking and to initiate creative ecstasy. That is because he believes in dialectics between the language of logic and the language of emotion: "Abstract cognition divorced from directly active effectiveness is unacceptable to us.” (Eisenstein, 1988, 155.) Following, intellectual cinema becomes a matter of synthesis, convergence, and togetherness. Eisenstein concludes: "The new art must set a limit to the dualism of the spheres of 'emotion' and 'reason.”' $(1988,158$.

\section{Two}

Since the early days of filmic attractions, it was felt that film experience should attract senses and emotions via closeness and directness of the presented events. At the same time the cinematic experience was such that mental engagement relied on the physical distance to the screen so that audiences felt close to the presented scenery on the one hand and would reflect the viewing process of the cinematic presentation on the other. The former describes an expansive 
and intentionally immersive media strategy. In was step by step improved by filmmakers and producers with the aim to establish film as a dynamic medium "bigger than life" that supersedes neighbouring art forms and media. The latter aspect of distancing the viewer from the identification with the presented spectacle to some degree goes hand in hand with the before described strategy of emotional overpowering. When both are not balanced, audiences may become too scared about plunging into presented events. For example, when physical distance and reality border between us, the viewers, and them, characters and action on screen gets too much conflated in today's applications of Augmented Reality, this will have destabilizing and resultantly dangerous effects on our reality awareness. Differently, the duality of seeing and knowing is rather enforced in the regular film viewing situation. By experience we have learnt to know that things from the screen that approach us much too big, too near and too fast cannot reach out across the media border, not even in immersive cinematic 3D.

In cinema, the fixed spatial distance to over-life-size screens; the temporal fixity of events that unfold in the course of the film or nowadays digital projection of film form; plus the reassuring certainty that we can leave the movie theatre any time, in short our knowledge about the constructedness of the presented illusion constitutes an uncircumventable condition. It is safeguarding our joyful embeddedness into foreign, strange worlds of viewing. This construction has proved to guarantee the stability of the cinematic institution. The interplay of nearness and distance and nearness combines two components: knowing that what we are seeing and hearing are media effects while we sensorially enjoy the constructed perceptual environment as if in real life. With the latter diversification of film beyond cinema, such as in multiple projections, expanded screen installations, and the incorporation of filmic projecting into interactive and participatory environments, we have entered the realm of digital computers. Here, the previously distinguishable parameters are heavily conflated and remediated. They not only appear in novel constellations, they also to serve different needs.

Nowadays we need to discuss how technological novelties are dynamically embedded into cultural imaginations about perceptual experiences, be it in film, in virtual reality, augmented reality, and all kinds of human-machine interactions that stress embodiment and active participation more than before. In view of media evolution from film to expanded media, we learn from research into convergence and remediation, that media development does not mean inventing the "new," but rather refashioning an existing network inclusive of physical, social, aesthetic, and economic components. As Bolter and Grusin put it: "For 
this reason, we can say that media technologies are agents in our culture without falling into the trap of technological determinism. New digital media are not external agents that come to disrupt an unsuspecting culture. They emerge from within cultural contexts, and they refashion other media which are embedded in the same or similar contexts.” (Bolter and Grusin 1999, 19.)

In many fields of film practice, we find artistic examples that refashion respectively readdress filmic principles in other media forms. They purposefully expand the viewing experience beyond the formal constraints of cinema. From an intramedial perspective, experimental film practices of the sixties and seventies appear to be particularly fruitful in further contextualising matters of seeing and sensing. They shed new light to the issues as they were articulated in painting and cinema before. In experimental tendencies of structural film, in particular, viewing experiences are closely linked to scrutiny of the embodiment of the spectator. The viewer is also regarded as an acting participant insomuch as film performances merge with electronic media followed by digital technologies. Among the variety of endeavours in the contemporary creative arts that are responsive to emerging electronic media, notably film installations with multiple screens and variable interferences in structural film of the seventies already play a leading role when it comes to connecting seeing and knowing in today's art. These expanded cinematic forms foreshadow an interplay of conventional film forms with human-machine interaction that will get further enlarged in more complex perceptual environments that use computers.

To exemplify the intermediary position of experimental film of the structural direction, I wish to point out the radical analysis of persistence of vision as it has been demonstrated in the experimental film installations by Paul Sharits. In the history of film, it is Sharits who is pioneering expansive visual forms with film that resemble the open structure of video processing, when he violently analyses the materials of film and the cinematic apparatus by questioning perception and projection. Sharits's work drives film in the form of frames to the limits of cinematic performance. He expands the concept of projecting film with multiple screen installations and aims to immerse the viewer in temporally and spatially disturbing perceptual film environments. His interest in the persistence of vision leads him to create distortions of the standard systems of film projection. The approach is twofold: Sharits uses projection with variable frame rates in order to interfere with the viewing impression of apparent motion, and he inserts frame cuts to interrupt the image and disturb temporal development using flicker effects.

Sharits was interested to radicalise filmic development in time. The point was that the tension between our understanding of the filmic development in 
time and the antagonistic, non-developmental concept of film as information "on light," is rendered sharp. Sharits's goal was to make the border between film and non-film perceptible by violently drawing the viewer's attention to recognizing at the same time the frames and their apparent motion. In this, Sharits focuses on the visibility of the transition from one frame to the next.

This is particularly evident in Epileptic Seizure Comparison (1976) [Fig. 1] in which the two screen loop projection is combined with the reflective walls of his specially designed film installation. Sharits explains how he wants to invert projection within the immersive space end confuse the viewer's emotional and analytic modes of perception. "Side walls must be smooth and be painted with reflective aluminium paint to exaggerate the frenetic pulsing of the screen images." (Sharits 2008, 353) Sharits, explicitly employs interval montage to merge performance and projection with the goal to destroying development. He superimposes two film strips (frames of a medical study on epilepsy and frames of pure colour) not to emphasize but to reduce action toward abstraction. Sharits uses the representational images of an epileptic seizure in a flickering structure of double projection of film that by itself resembles the rhythm of an epileptic seizure and immerses viewers into a performance of the projection of images of light and colour that withholds the flow of action.

The reduction of visual information through its pulsating rhythm blurs the boundaries of external sight and inner vision. With the reduction of development through variable speeds, reflection on the viewing process shifts from knowing to seeing inasmuch as Sharits visualizes the paradox of an individual frame in motion. Once we can see through the structure of projected film images and perceive the individual frame, but also know at the same time that the image in motion that we see is a necessary illusion, it will be harder for the viewer to interpret film movement in the sense of directional development. Sharits intervention is twofold: it generates awareness of the still frame and, at the same time, blurs the sense of differentiation.

\section{Three}

Following, I wish to point out positions in contemporary creative arts that rework the convergence of the two spheres of recognition, seeing, and sensing from the perspective of computer media and digital simulation. The questioning of visual recognition is an important factor in creative practices that investigate participation and action in multisensory and digitally modulated environments. In view of 
densely networked media environments as they determine our contemporaneity and conflate the experience of present, past, and future, visual cognition as such has come under critique, particularly in multisensory experiments. A shift takes place in the key parameters of seeing and knowing when digital media render the familiar strange and question the objectification of subjective experience in essence. The necessity of cognitive understanding when faced with a virtual-real simulated reality is demonstrated symptomatically in the well-known science fiction film The Matrix (directed by Andy and Lana Wachowski, 1999). To remind: the central character, Neo, can only intervene as a force for renewal in the elastic transitions from virtuality to reality - filmically shown via computer graphics, green screen, and motion control techniques - because he understands the binary code behind the digital reality as columns of numbers, because he doesn't believe what he sees and perceives, but acts on what he knows from critical analysis. Visual, sensual understanding gives way to cognitive knowledge.

The task of critique of visuality is further sharpened in multimedia arts. Postcinematic, multimedial, and large screen presentations examine the motivation of medical and military-industrial faculties to envelope simulated environments more and more seamlessly. They can show aesthetically, how feeling and seeing intentionally converge with the employment of augmented tools respectively composite viewing technologies, and also demonstrate inasmuch one-sided upgrade of sense perception rather cuts off our curiosity to get to know what is going behind the scenes, in the real reality devoid of the screens. My examples are: Gina Czarnecki's shifts of scale, Seiko Mikami's bodily encounter with machine behaviour, and Masaki Fujihata's advocacy to maintain difference and distance in sensing as well as in knowing as the basic condition for a living interaction.

While technical qualities of computer simulation and control have introduced the possibility of simultaneously virtualizing various processes at various places, "in actual fact" and without bothering about physical boundaries, British based media artist Gina Czarnecki researches the sectors of medicine and biology, where the intention is to undertake scientific interventions in the human body and the living environment. She focuses on the question of the normative scale applied to body shapes, mutations, infections, and viruses, and to this end she presents filmic installations with projected images of digitally simulated deviations and variations of physicality. Universal scaling for categorizing information concerning the human body, identity, and person dominate in biology, medicine, and genetics but also in aesthetics, and Czarnecki retranslates them from the general (global) scale back into the individual (local) scale. 
Against this background, Czarnecki investigates the aesthetic beauty of digitally modified body images of dance movements, which she shrinks visually and knits together into something akin to meshes, until they lose any sort of subjectivity and appear like living cell structures. Her works Spine (outside projection, Newcastle upon Tyne, UK, 2006) which uses material of the earlier Nascent (film version in collaboration with the Australian Dance Theater, UK, 2005), use variable projection in filmic installations on large-scale surfaces in urban spaces to illuminate correspondences between the biological and technological multiplications of manipulated life forms. Cosmetic and surgical modifications, prostheses, sex changes, cloning, and genetic "corrections" form common points of reference. When we, as audience, are confronted with the artistic selection of the naked bodies presented in the installation, this range of questions gains further significance as it engages with biomedical research in a direction belonging to ethnological and cultural politics.

In the moving images of Nascent [Fig. 2] as a filmic installation, digital composition of dance forms overlays and shrinks the bodies to abstract units of information. That is because changing the scale, together with reduplicating the image segments, makes the dancers into chains of bodies linked to each other, into blurred ribbons and pulsating light formations. The entanglement of people so presented tends much more to promote distancing, an effect underlined by an accompaniment sounding metallic and synthetic. The expression of some humanity does clearly persist so that border zones of virtualization and abstraction tip over into dehumanization.

That effect points explicitly to the procedure customary in scientific, biologicalmedical, and military operations of abstracting away from subjects, people, and their lives. In an interview, Czarnecki names the point of reference in which cognitive decisions made in virtuality based on sense-making of dehumanizing visual pattern have real effects on the life and death of individuals. "Science, law, medicine, and the military present images and we take them as authentic, but so many of them are artificially constructed. And art can present fact but it's always perceived as fiction. Medicine has been developing imaging technologies to prove the existence of something - scanning, the ultrasound, the infrared. I was on a train journey in the UK and I sat opposite a gulf war engineer and he said that 'of course we kill people but we see them as little green dots on the screen and we just zap them.'” (Czarnecki in Branigan, 2006.)

In this context, an aesthetic-poetic work, like Czarnecki's visualization of disembodiment, can count as a sharp critique of such linking of seeing and 
knowing in operations that use augmented reality to produce scientific knowledge devoid of any sensitivity. The technological feasibility dominates in employing augmented reality for military and medical goals, and the dimension of the personal-subjective is suppressed in telerobotic perceptual contact.

The outside projection Spine, first installed in public space in Newcastle upon Tyne 2006 and measuring 25 by 17 meters, works in the opposite direction. In it, the personal-subjective aspect specifically corresponds to the location, resembles a model, and shifts into a dimension appropriate to exhibiting and viewing in the public sphere. With the use of the filmic material from Nascent, the digitally manipulated dancers here also occupy the foreground like masses of cells and are moving around naked. As a result, the medial presentation of Spine shows the personal aspect as an example of the shifting of boundaries from the intersubjective into the supposedly objective public sphere of activity, where the representation is cut off from familiarity and emotional responses. This discrepancy between representation and what is represented refers to the way computer technologies have invaded all areas of the media like a virus and are dominating our sense perception.

Another example gives Seiko Mikami with her large-scale spatial installation Desire of Codes (Yamaguchi Center for Arts and Media, 2010, also exhibited at InterCommunicationCenter, Tokyo, 2011) that addresses our sense and sensibility in computer environments. It equally poses the question of what sort of "inherent behavior" the computer codes might have, particularly when their capacity to measure and move takes on an organic character.

On the wall of the installation space, Mikami mounted ninety devices that are equipped with search arms that have small LED pointers and with cameras and sensors to detect movement and sound of the visitors when they approach the wall. The whole structure is targeting us as if the technical apparatuses and the humans were different species entering into dialogue with each other. As the lights and the cameras follow the visitors' movements in space, the resulting effect is that the devices, which are driven by audible motors, move their arms "searching for" individual visitors like a buzzing swarm of mosquitoes. Various measuring sensor data (light, ultrasonic, and infrared sensors) are combined to create the responsive effect.

Each of the combined sensors and the cameras do capture and measure independently, but they are networked together in a computer system and attuned to each other in a sort of "group behavior." The audience for this "industrial invention" not only acts as an interface and has the difference but also the similarity 
between themselves and the machine to be presented to its eyes and ears via extremely miniaturized interfaces. Because the devices resemble the size of toys, they become almost flattering interfaces, which appear harmless and handsome, and not like control and surveillance apparatuses. Notably is the cultural aspect of reference to miniaturized computers, electronic toys, and gadgets, which have spread like insects through the private and public sectors in Japan and South-East Asia. In her work, Mikami makes us aware of a close and personal relationship between the human perception in general and the individual senses and how they are affected, on the other hand. She also draws our awareness to the humanoid behavior of increasingly small and smart robots and further machine devices that are equipped with sensory instruments to detect us, target our behavior, and go after us. It is precisely the kind of interface that is built by Mikami herself and not using standardized mechanism, which evokes the experience of in-betweenness and makes us aware of our modes of perception in relation to the surrounding that is machine driven and operates by a chain of codes.

Mikami in the other two parts of the installation further explores her view of the desire of codes seen as a chain of behavior and response in correspondence to social behavior. Once we move away from the Wriggling Wall [Fig. 3] with its 90 units targeting at us, we find ourselves surrounded and equally targeted by huge, over-live-size six robot search arms that hang from the ceiling and reach into the space. The robot arms follow the task to express desire of codes by way of following and recording movements of the visitors. The arms are equipped with cameras and projectors, and simultaneously project the recorded footage onto the floor where we move. In the third part of the installation, the Compound Eye [Fig. 4] Mikami further focuses the anthropocentric effect of the miniature mechanical arms of the Wriggling Wall with their LED's trained on us like searchlights.

In the image structure of the Compund Eye imitating an insect's eye, current and past recordings of viewers can interfere via computer programs with data information from search engines in the Internet, which have access, in real time and permanently, to surveillance cameras in places all over the world. The model of the hexagon here becomes a permeable interface of global surveillance: it makes us aware of how personal experience is caught up in worldwide data transfer. The philosophy of the installation is testing our experience of the behavior of machines as it is driven by codes. We are also invited to think about the appetite respectively the desire of the code to randomly grasp and process data from anywhere at any time and "produce" endless chains of information input and output. The installation demonstrates its own structural components 
such as repetition in the stream of data and thereby makes us aware of our own desire to create and produce something and at the same time shows our limits to influence and actually control the machine process with which we interact.

Another media artist from Japan, Masaki Fujihata, also reflects the interplay of seeing and sensing by employing scientific measuring instruments for art purposes. He uses perceptual instruments in radicalized ways as personally modified technologies and creates model-like science-scapes as a new form of interaction. This Masaki Fujihata tests out in the area of the contact almost made between orchids and us. The difficulty of synchronizing computers in networks, as is necessary for performing exact interactions between us and machines, forms the point of departure for this experimental arrangement with orchids.

With Orchisoid (Japan, 2001-2007) [Fig. 5] the attempt is made to communicate between humans and machines without any sort of coding. The setup is equipped with measuring instruments, as in a scientific laboratory. The interactive distance between individual plants is measured, together with their behaviour toward each other and their sensitivity to moisture, as when one of two plants standing close together is watered but the other is not. The plants are, in addition, tested for their sensitivity like bio-robots, lifted onto a hydraulic platform and "driven" in all directions at high speed, while projected images of a botanical garden run past them and imitate a "real" environment for the plants. The project was developed in collaboration with the botanist Yuji Dogane, and Fujihata sees it as standing at the juncture of robotics and nature: "In Botanical Ambulation Training footage filmed while walking through a botanical garden is being projected onto a wall. Orchids (mainly Cattleya) can see these projections from the baskets they are planted in. The aspects of tremor (acceleration, geomagnetism, inclination) in the images are being translated into impulses that shake the platform the flower baskets are sitting on, so that the flower baskets move perfectly in sync with the trembling of the images on the wall. Therefore, from the perspective of the orchids it must feel as if they were being carried in the hand (that actually holds the camera) around the garden. [...] What in the world could it be that the orchids are thinking while swaying gently on their metal pistons, watching pictures of a shaking greenhouse, and devoting themselves to 'reproduction activities?"' (Fujihata, 2007.)

This new sort of experimental arrangement would be misread as a simple critique of technology; it rather advocates dialogue that is based on difference and distance as the condition for real interaction. That is because, when the sensory contact becomes too close and too strong, the vitality in dialog is put at risk. To that extent, this demonstration with plants sensitive to contact has a 
component criticizing the media by focusing on the ostensibly desirable removal of any distance and difference in all versions of touch media, something that here does not, however, appear as a goal or a way to more communication. On the contrary, Fujihata is in accord with Mikami and Czarnecki to provoke dialog across difference in aesthetically constructed perceptual environments so that in the interplay between sensation and knowledge something new and something different can arise.

\section{References}

Beckett, Ronald Brymer, ed. 1970. John Constable’s Discourses. Ipswich: Suffolk. Bolter, Jay David and Richard Grusin. 1999. Remediation. Understanding New Media. Cambridge, Mass: MIT Press.

Brannigan, Erin. 2006. "Gina Czarnecki Interview." September http://www. ginaczarnecki.com/storage/press/erin_b_contagion_01-09-2006.pdf. Last accessed at: 28. 08. 2013.

Eisenstein, Sergej M. 1988. Perspectives. In M. Eisenstein. Writings, 192234 Selected Works, vol. 1, ed. Richard Tayler, 151-160. London: BFI and Bloomington: Indiana University Press.

Fujihata, Masaki and Yuji Dogane. 2007. Botanical Ambulation Training. In Silent Dialogue, exhibition catalogue Tokyo: 2007.

Sharits, Paul. 1976 [2008]. Epileptic Seizure Comparison. In: Buffalo Heads. Media Study, Media Practice, Media Pioneers, 1973-1990, eds. Woody Vasulka and Peter Weibel., Cambridge, Mass: MIT Press. 


\section{List of Figures}

Figure 1. Paul Shartis, Epileptic Seizure Comparison (1976).
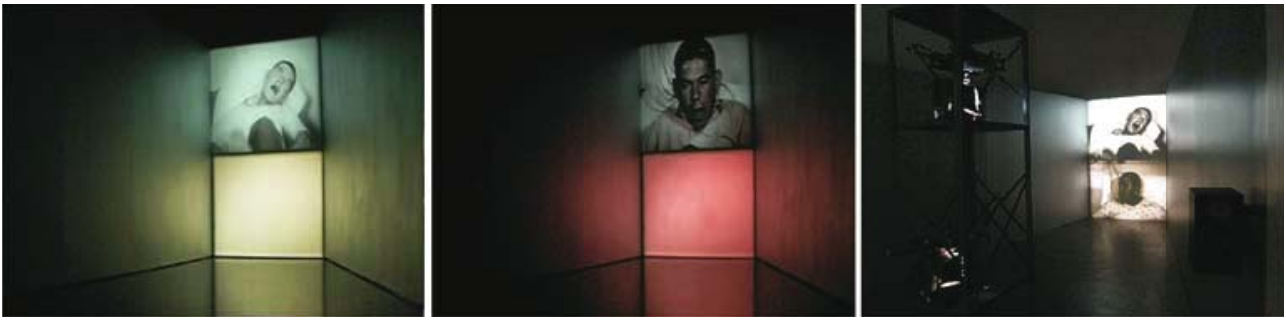

Figure 2. Gina Czarnecki, Nascent (2005).
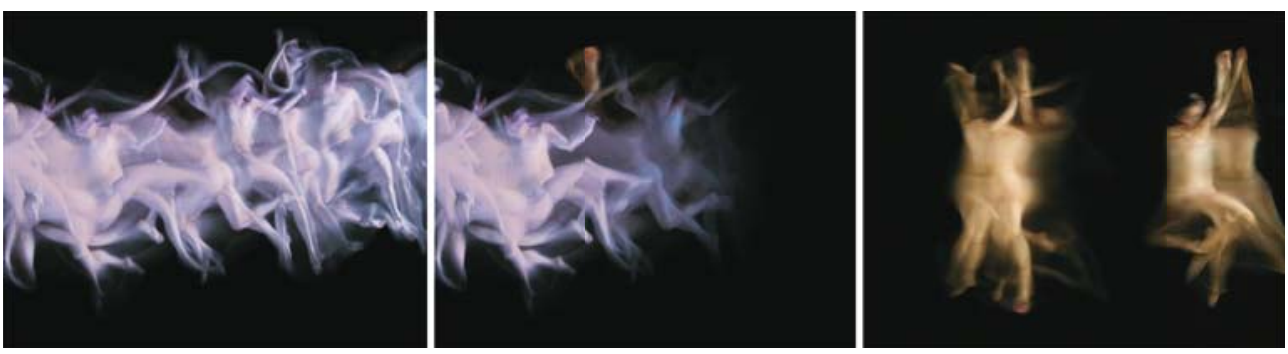

Figure 3-4. Seiko Mikami's Desire of Codes: Wriggling Wall, Compound Eye (2010, 2011), Figure 5. Masaki Fujihata: Orchisoid (2001-2007).
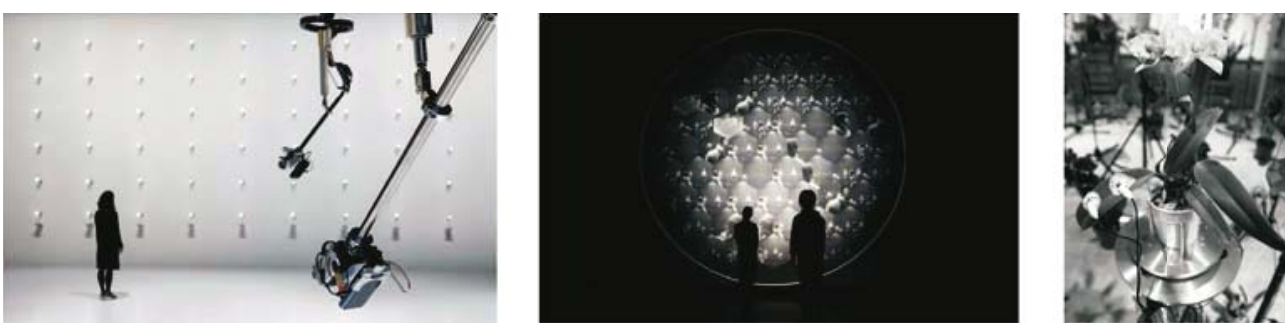